\section{New directions in drug approval}

$M$ ajor changes underway in Canada's drug regulatory system will have significant implications for how quickly new drugs are approved and how well Health Canada monitors the safety of drugs already on the market.

The Throne Speech that opened the parliamentary session at the end of September 2002 enunciated a new direction in regulatory activities; this entailed "speed[ing] up the regulatory process for drug approvals to ensure that Canadians have faster access to the safe drugs they need." "To give concrete meaning to that pledge, in the 2003 budget the government committed \$190 million in new money over the 5-year period 2003-2008 "to improve the timeliness of Health Canada's regulatory processes with respect to human drugs."

Out of the $\$ 190$ million, $\$ 40$ million has already been allocated for fiscal year 2003/04, of which $78 \%$ (\$31.2 million) will go toward "improved regulatory performance" - mainly an effort to eliminate the backlog in drug approvals and to ensure timeliness in getting drugs onto the market. Various reasons for delays in the Canadian drug approval system have been identified. These include a lack of human resources, poor coordination between assessments of the chemistry and manufacturing data and of the safety and efficacy data, delays in receiving requested additional information from manufacturers, and the bureaucratic rigidity that results from situating the approvals system within Health Canada rather than as a standalone agency. Some of these p problems might be amenable to correction with more money, but not all of them are.

In contrast, only $\$ 2.5$ million of the $\$ 190$ million is allocated to the Marketed Health Products Directorate, which is charged with monitoring the safety and performance of drugs already approved. ${ }^{3}$ This division in funding allocation is occurring at a time when, because of a lack of resources, the directorate has had to stop routinely trying to assign causality when evaluating adverse drug reaction reports. Information from each adverse drug reaction report that is received is entered into a number of fields in the Canada Adverse Drug Reaction Information System (CADRIS) database. Now, because of increased workload and funding contraints, the number of essential fields in the CADRIS database has been reduced, such that the "causality" field is no longer being systematically used (Dr. Chris Turner, Director General, Marketed Health Products Directorate, Health Canada: personal communication, 2004),

At a December 2003 meeting of the Health Products and Food Branch (HPFB) Advisory Committee on Management, I asked what the priorities were in directing the $\$ 190$ million and was offered 4 rationales for an emphasis on speeding up approvals: (1) If there was no improvement with respect to timeliness and the backlog of approvals, then it would be difficult to move ahead in other areas; (2) this is an area where the HPFB has the capacity to take action; (3) emphasis was given to this particular issue in the Speech from the Throne; (4) the $\mathrm{HPFB}$ has received the most criticism with respect to timeliness and the backlog.

Who is criticizing Health Canada about approval times, and why is timeliness so important that it reaches the Throne Speech and garners such a large share of the new money? Patient groups are naturally concerned when they perceive that effective treatments are being delayed, and Canada does lag behind other countries in the speed at which it approves drugs given priority status. For

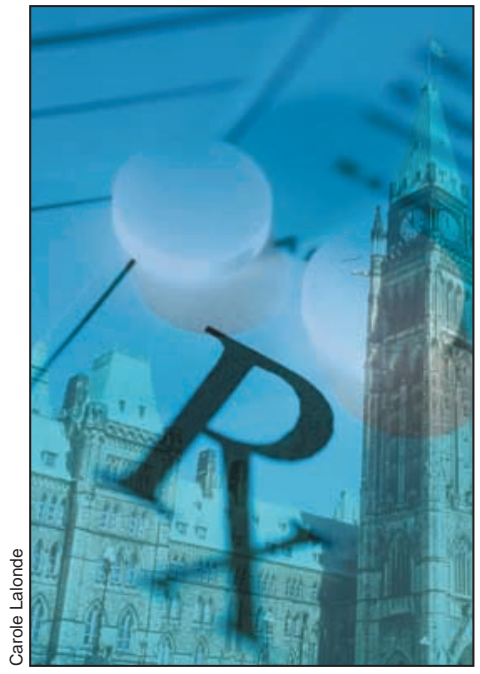

this class of drugs it takes an average of 317 days to get through the Canadian system, as compared with 232 days in the United States. ${ }^{4}$ However, fewer than $9 \%$ of the new active substances marketed in Canada qualify as either breakthrough products or significant therapeutic improvements. ${ }^{5}$

The loudest and most influential voice calling for faster drug approvals comes from the brand-name industry. In a recent document, Rx\&D, the organization representing the brand-name industry in Canada, emphasizes the excessive length of time that it takes to get a drug approved. ${ }^{6}$ From the point of view of return on investment, industry's preoccupation with timeliness makes perfect sense; whether that preoccupation is warranted from a public health point of view is another question.

Timeliness in the approval process may take on even greater importance in the near future. During the last parliamentary session, Bill C-212 was passed $^{7}$ to deal with the user fees that various arms of government collect from industry for delivering services. Starting in 1994, pharmaceutical companies were charged fees for each new drug they submitted for approval; by 1999-2000, these 
user charges paid for close to $50 \%$ of the overall cost of running the drug regulatory system. ${ }^{8}$ Bill C-212 was introduced as a private member's bill by Liberal Member of Parliament Roy Cullen with the explicit aim, according to Cullen, of "bring[ing] greater transparency and accountability to federal government departments and agencies when they attempt to recover costs through user fees." The bill was also intended to provide for more parliamentary oversight when user fees are introduced or changed, improved linkages between user fees and performance specifications and standards in the federal government, and greater stakeholder participation in the fee-setting process.

Strong private-sector interest in this legislation was expressed through the Business Coalition on Cost Recovery, which included the brand-name pharmaceutical companies. The coalition was particularly supportive of aspects of the bill that are meant to ensure that user fees are consistent with the level and value of the services provided. ${ }^{7}$ In this regard, Bill C212 provides for Canadian services to be compared with similar ones offered by our major trading partners. If services are not adequate, government departments stand to forfeit part of the user fees.

How Bill C-212 will be applied to our drug regulatory system is unknown at this point, but, with Canadian approval times lagging behind those in the United Kingdom and the United States, it is conceivable that Health Canada might have to pay back some of the money that it collects. Faced with that possibility, Health Canada could be tempted to put even more resources and money into the approval process at the expense of the postmarketing surveillance system. Setting and measuring timelines for drug approvals is relatively straightforward, but how do we set standards for how long it should take to act on adverse drug reaction reports?

To satisfy all of its various stakeholders, Health Canada will have to balance timeliness and safety. How it goes about this delicate task will be interesting to watch.

\section{Joel Lexchin}

Associate Professor

School of Health Policy and

Management

York University

Emergency Department

University Health Network

Associate Professor

Department of Family and

Community Medicine

University of Toronto

Toronto, Ont.

\section{References}

1. Government of Canada. The Canada we want: Speech from the Throne to open the Second Session of the ThirtySeventh Parliament of Canada. Available: www.sft-ddt.gc.ca/vnav/07_e.htm. (accessed 2004 Jul 6).

2. Department of Finance, Canada. Build ing the Canada we want. Budget 2003: investing in Canada's health care system [cat no F1-23/2003-4E]. Ottawa: The Department; 2003. Available: www.fin .gc.ca/budget03/booklets/bkheae.htm (accessed 2004 Jul 6).

3. Health Canada. Improving Canada's regulatory process for therapeutic products: building the action plan. Public Policy Forum multi-stakeholder consultation; 2003 Nov 2-3. Available: www.ppforum .ca/ow/ow_e_05_2003/Presentation \%20 _Overview_of_Action_Plan.pdf (accessed 2004 Jul 6).

4. Rawson NSB. Timeliness of review and approval of new drugs in Canada from 1999 through 2001: Is progress being made? Clin Ther 2003;25:1230-47.

5. Patented Medicine Prices Review Board. Annual report 2001. Ottawa: The Board; 2002.

6. Rx\&D (Canada's Research-Based Pharmaceutical Companies). Improving bealth through innovation: a new deal for Canadians. Ottawa; 2002. Available: www.canadapharma.org/Media_Centre/Special_Reports/Brief-innovationsept-02_e.pdf (accessed 2004 July 6).

7. Business Coalition on Cost Recovery Roy Cullen congratulated on passage of C-212 [news release]. 2004 Mar 26. Available: www2.cdn-news.com/scripts /ccn-release.pl?/2004/03/26/0326095n .html? cp=baystreet 2 (accessed 2004 Jul 6).

8. Health Canada, KPMG Consulting. Review of the Therapeutic Products Programme cost recovery initiative. Executive summary. Available: www.hcsc.gc.ca/hpfb-dgpsa/tpd-dpt/exec-sum _e.html (accessed 2004 Jul 6).

9. Notes for Roy Cullen. Canadian Consumer Specialty Products Association Annual Federal Government Interface Conference 2004. Ottawa; 2004 Feb 3. Available: www.roy cullen.com/reports/notes_C212 2004 .htm (accessed 2004 Jul 6).

\section{Holiday Review 2004 Call for Papers}

We're looking for creative contributions for CMAJ's Holiday Review 2004. Humour, personal reflections, history of medicine, off-beat scientific papers and postcards from the edge of medicine are welcome.

Send your offering to the Managing Editor, Josephine Sciortino (800 663-7336 x2366; josephine.sciortino@cma.ca). Articles should be no longer than 1200 words, and photographs or illustrations are encouraged.

The deadline for submissions is September 13, 2004.

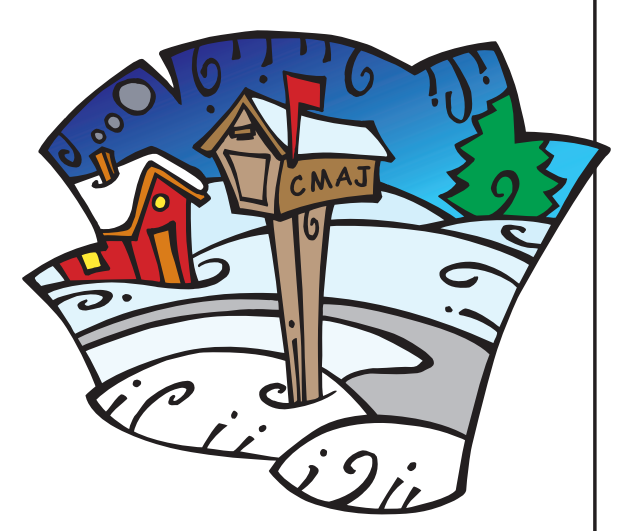

